\title{
S. Typhimurium sseJ gene decreases the S. Typhi cytotoxicity toward cultured epithelial cells
}

\author{
A Nicole Trombert, Liliana Berrocal, Juan A Fuentes, Guido C Mora*
}

\begin{abstract}
Background: Salmonella enterica serovar Typhi and Typhimurium are closely related serovars as indicated by $>96 \%$ DNA sequence identity between shared genes. Nevertheless, $S$. Typhi is a strictly human-specific pathogen causing a systemic disease, typhoid fever. In contrast, $S$. Typhimurium is a broad host range pathogen causing only a selflimited gastroenteritis in immunocompetent humans. We hypothesize that these differences have arisen because some genes are unique to each serovar either gained by horizontal gene transfer or by the loss of gene activity due to mutation, such as pseudogenes. S. Typhi has $5 \%$ of genes as pseudogenes, much more than $\mathrm{S}$. Typhimurium which contains $1 \%$. As a consequence, S. Typhi lacks several protein effectors implicated in invasion, proliferation and/or translocation by the type III secretion system that are fully functional proteins in $S$. Typhimurium. SseJ, one of these effectors, corresponds to an acyltransferase/lipase that participates in SCV biogenesis in human epithelial cell lines and is needed for full virulence of S. Typhimurium. In S. Typhi, sseJ is a pseudogene. Therefore, we suggest that sseJ inactivation in S. Typhi has an important role in the development of the systemic infection.

Results: We investigated whether the S. Typhi trans-complemented with the functional sseJ gene from S. Typhimurium (STM) affects the cytotoxicity toward cultured cell lines. It was found that S. Typhi harbouring SSeJ STM $_{\text {S }}$ presents a similar cytotoxicity level and intracellular retention/proliferation of cultured epithelial cells (HT-29 or HEp2) as wild type $S$. Typhimurium. These phenotypes are significantly different from wild type $S$. Typhi
\end{abstract}

Conclusions: Based on our results we conclude that the mutation that inactivate the sseJ gene in S. Typhi resulted in evident changes in the behaviour of bacteria in contact with eukaryotic cells, plausibly contributing to the $S$. Typhi adaptation to the systemic infection in humans.

\section{Background}

Salmonella enterica serovar Typhi (S. Typhi) is a human-restricted pathogen that causes enteric fever or typhoid. Salmonella enterica serovar Typhimurium (S. Typhimurium) is considered a broad host range pathogen that causes gastroenteritis in several warm-blooded animals such as calves and humans, but produces a typhoid-like systemic infection in mice [1-3]. Although the mechanism by which serovar Typhimurium causes gastroenteritis is well studied, less is known about the pathogenesis of the serovar Typhi. One limitation to the study of typhoid fever is the absence of a good animal model. For this reason, although the $S$. Typhimurium mouse model has been used to infer $S$. Typhi important

\footnotetext{
* Correspondence: gmora@unab.cl

Laboratorio de Microbiologia, Facultad de Ciencias Biologicas y Facultad de Medicina, Universidad Andres Bello, Santiago, Chile -
}

virulence mechanisms by the expression of $S$. Typhi genes in $S$. Typhimurium, the information derived from infection of mice is limited mainly because the virulence factors are tested in an heterologous system. Furthermore, S. Typhimurium does not cause typhoid in humans, suggesting that genetic differences between both serovars are crucial for disease development.

The evolution of a broad host pathogen, such as $S$. Typhimurium, to a host-restricted pathogen, such as $S$. Typhi, might have occurred by (i) the acquisition of genetic material through horizontal gene transfer, (ii) genome degradation (i.e., the loss of genetic information by deletion or pseudogene formation) or (iii) a combination of both of these mechanisms $[4,5]$. The acquisition and persistence of DNA segments containing genes with pathogenicity or virulence functions (i.e., pathogenicity islands) will depend on the advantage they confer to the

C Biomed Central

(c) 2010 Trombert et al; licensee BioMed Central Ltd. This is an Open Access article distributed under the terms of the Creative Commons Attribution License (<url>http://creativecommons.org/licenses/by/2.0</url>), which permits unrestricted use, distribution, and reproduction in any medium, provided the original work is properly cited. 
pathogen infectious cycle. Thus, bacteria with a great ability to colonise different environments, such as Pseudomonas aeruginosa, generally have larger genomes than those that survive in restricted niches [6].

The phenomenon by which a microorganism becomes adapted to its host involves the loss of genetic functions resulting in pseudogene generation, a process termed "reductive evolution". This process has been observed in human-adapted pathogens such as Shigella flexneri, Mycobacterium leprae and Salmonella Typhi $[7,8]$. For example, the loss of the ompT gene in Shigella confers a virulent phenotype by allowing bacteria to transmigrate across eukaryotic cells $[9,10]$. In the case of Salmonella, some serovars have accumulated mutations that enhance their survival within their respective hosts. For example the poultry-adapted $S$. Pullorum and $S$. Gallinarum serovars are non-motile because they have a point mutation in the $f l g K$ gene $[11,12]$. When $S$. Enteritidis and $S$. Typhimurium are isolated from infected poultry, these bacteria are frequently non-motile, suggesting that the niche occupied in birds can select against flagellation [13]. These non-motile $S$. Typhimurium strains have been shown to be non-virulent when used to infect mice. Thus, in the S. enterica, the adaptation to a particular vertebrate host seems to drive the loss of virulence factors for some serovars. The result of this adaptation may contribute to the narrowing of the host range and to the development of host specificity [14].

$S$. Typhi is an intracellular facultative pathogen that contains over 200 pseudogenes, nearly $5 \%$ of its whole genome $[15,16]$. Several of the mutations that gave rise to these pseudogenes occur in systems related to pathogenicity mechanisms. For example, the $S$. Typhimurium sseJ gene encodes an effector protein regulated by Salmonella pathogenicity island 2 (SPI-2) $[17,18]$. SPI-2 regulated genes are related to bacterial intracellular trafficking and proliferation, and encode a protein complex known as the type III secretion system (T3SS). The T3SS mediates the injection of effector proteins from bacteria into eukaryotic cells [19-21]. These effector proteins modulate the $S$. Typhimurium endocytic pathway and allow the establishment of bacteria in a specialised vacuole termed the Salmonella-containing vacuole (SCV) [22]. Late stages of SCV synthesis include the formation of tubular membrane extensions known as Salmonella-induced filaments (Sifs). Sifs are thought to result from the fusion of late endocytic compartments with the SCV and their formation requires at least five SPI-2-dependent effectors: SifA, SseF, SseG, SopD2 and SseJ [23-26]. In this context, S. Typhimurium sseJ encodes an acyltransferase/lipase that participates in SCV biogenesis in human epithelial cell lines [25,27-29]. The coordination of SseJ and SifA is required for bacterial intracellular proliferation [30]. Some studies have shown that SseJ is needed for full virulence of $S$. Typhimurium in mice and for proliferation within human culture cells [31].

$S$. Typhi lacks several effector proteins that are crucial for the pathogenicity of the generalist serovar $S$. Typhimurium [29]. The absence of these proteins could contribute to the specificity of the human-restricted serovars, and could play a role in evolutionary adaptation. In S. Typhi, sseJ is considered a pseudogene. In this work, we studied the effect of trans-complementing $S$. Typhi with the $S$. Typhimurium sseJ gene and assessed the phenotype in human cell lines. Our results show that the presence of the sseJ gene induces phenotypic changes in cytotoxicity and in intracellular proliferation of $S$. Typhi in human epithelial cell lines. Our results suggest that the loss of SseJ function contributes to the development of a systemic infection in $S$. Typhi.

\section{Results}

sseJ is a pseudogene in S. Typhi

To assess whether the sseJ locus is a pseudogene in the serovar Typhi, we compared the available sequences of $S$. Typhi Ty2, S. Typhi CT18 and S. Typhimurium LT2 $[15,32,33]$. We observed that the sequence corresponding to sseJ in $S$. Typhi is a 3' partial remnant of $141 \mathrm{bp}$, in contrast with the complete ORF found in $S$. Typhimurium (1227 bp). In order to corroborate these bioinformatics results, we designed a PCR assay with two sets of primers. The primers SseJ1Tym + SseJ2Tym yield a $1460 \mathrm{bp}$ amplicon only when sseJ is complete, while the primers SseJRT1 + SseJRT2 yield a $127 \mathrm{bp}$ amplicon if the 3' sseJ locus is present (Figure 1). As shown in Table 1 we observed a PCR product with the SseJRT1 + SseJRT2 primers in all the strains tested, including the reference strains ( $S$. Typhi CT18, $S$. Typhi Ty2 and $S$. Typhimurium LT2) and $S$. Typhi clinical strains obtained from Chilean patients (STH collection). Nevertheless, we observed a PCR amplicon with the SseJ1Tym + SseJ2Tym primers only when the $S$. Typhimurium genomic DNA was used as template, strongly suggesting that the $s s e J$ gene is an incomplete gene (i.e., a pseudogene) not only in the $S$. Typhi Ty2 and CT18 strains, but in all the Typhi clinical strains tested. To independently assess this hypothesis, we performed a Southern blot using the $1460 \mathrm{bp}$ amplicon as a specific probe (Figure 2). The annealing of the probe with the EcoRV digested genome of $S$. Typhimurium yielded a $3450 \mathrm{bp}$ fragment, while in $S$. Typhi, we observed a $1800 \mathrm{bp}$ fragment. As shown in Figure 2 our data indicated that the presence of the pseudogene in S. Typhi CT18 is conserved in the $S$. Typhi clinical collection (STH). Therefore, the sseJ pseudogene seems to be a feature in serovar Typhi that distinguishes it from the serovar Typhimurium. S. Typhi STH007 presents no 


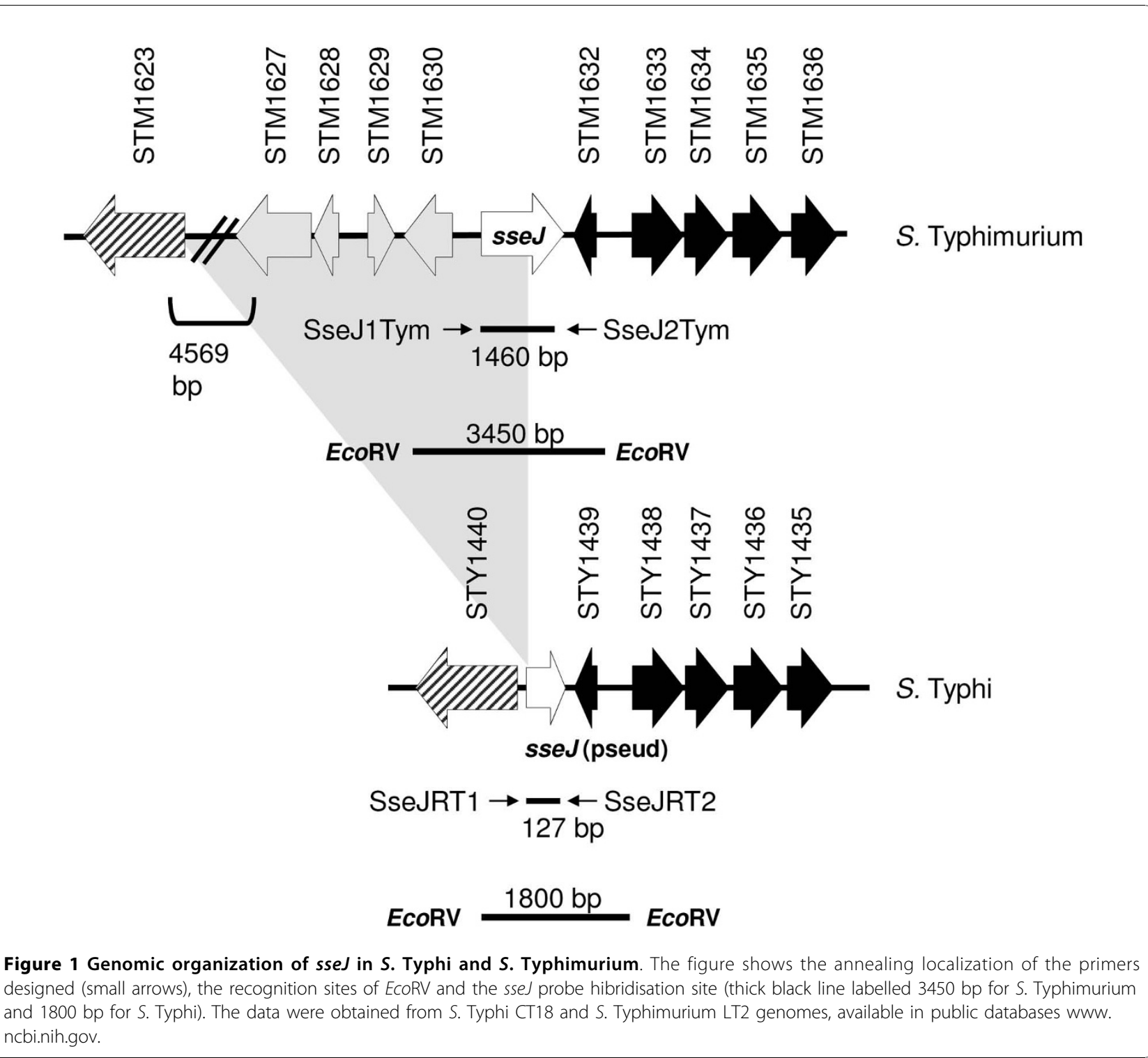

hibridisation with the probe, showing that this strain presents a larger deletion in the sseJ locus compared with other strains tested. S. Typhi STH2370 showed a slightly larger fragment than the other $S$. Typhi clinical strains presumably because of point mutations that changed the EcoRV restriction sites. Therefore, serovar Typhi has a genetic mutation in sseJ gene correlating with the previous studies made in strain CT18. We reasoned that the sseJ gene in the serovar Typhi is inactivated.

\section{S. Typhi harbouring the $S$. Typhimurium sseJ gene exhibits a decreased disruption of HT-29 polarised monolayers}

If the loss of SseJ function in S. Typhi is advantageous for the interaction of bacteria with host cells, we should observe that wild type $S$. Typhi will present a different behaviour than the $S$. Typhi harbouring the $S$. Typhimurium sseJ gene when they are in contact with eukaryotic cells. This hypothesis was first tested by infecting polarised HT-29 monolayers with the strains under study using a modified transepithelial migration assay that included addition of gentamicin (after $1 \mathrm{~h}$ of infection, see Materials and Methods) into the upper chamber (black arrow, Figure 3). As shown in Figure 3 the recovered $\mathrm{CFU} \times \mathrm{ml}^{-1}$ represented the bacteria which migrated to the lower chamber and survived the presence of the gentamicin that passed through the cell monolayer. If the integrity of the monolayer is disrupted by bacteria, gentamicin will leak through the lower chamber decreasing the recovered $\mathrm{CFU} \times \mathrm{ml}^{-1}$. If the monolayer is not disrupted, the recovered CFU $\times \mathrm{ml}^{-1}$ 
Table 1 PCR and Southern blot analysis of sseJ gene in S. Typhimurium vs. S. Typhi isolates

\begin{tabular}{|c|c|c|}
\hline Strain & $\begin{array}{c}\text { PCR } \\
1460 \text { bp }\end{array}$ & $\begin{array}{c}\text { PCR } \\
127 \text { bp }\end{array}$ \\
\hline \multicolumn{3}{|l|}{ Strains } \\
\hline \multicolumn{3}{|l|}{ Serovar Typhimurium } \\
\hline ATCC14028s & + & + \\
\hline LT2 & + & + \\
\hline \multicolumn{3}{|l|}{ Serovar Typhi } \\
\hline STH2370 & - & + \\
\hline STH001 & - & + \\
\hline STHOO4 & - & + \\
\hline STH005 & - & + \\
\hline STH006 & - & + \\
\hline STH007 & - & + \\
\hline STH008 & - & + \\
\hline STH0O9 & - & + \\
\hline Ty2 & - & + \\
\hline
\end{tabular}

should remain essentially constant over the same time course. As observed in Figure 3 the recovered CFU $\times$ $\mathrm{ml}^{-1}$ corresponding to $S$. Typhimurium 14028 s presented a slight decline over the time course of the assay (white diamonds), suggesting that the monolayer integrity is not largely affected by bacteria. In contrast, the CFU $\times \mathrm{ml}^{-1}$ of $S$. Typhi STH2370 recovered from the lower chamber abruptly decreased until they became undetectable, strongly suggesting that the gentamicin leaked into the lower chamber due to a monolayer disruption (black squares). When $S$. Typhi were complemented with the $S$. Typhimurium sseJ gene ( $s s J_{\mathrm{STM}}$ ) (in the pNT005 plasmid, see Materials and Methods), and used to infect the monolayer, we observed that the corresponding recovered $\mathrm{CFU} \times \mathrm{ml}^{-1}$ remained essentially

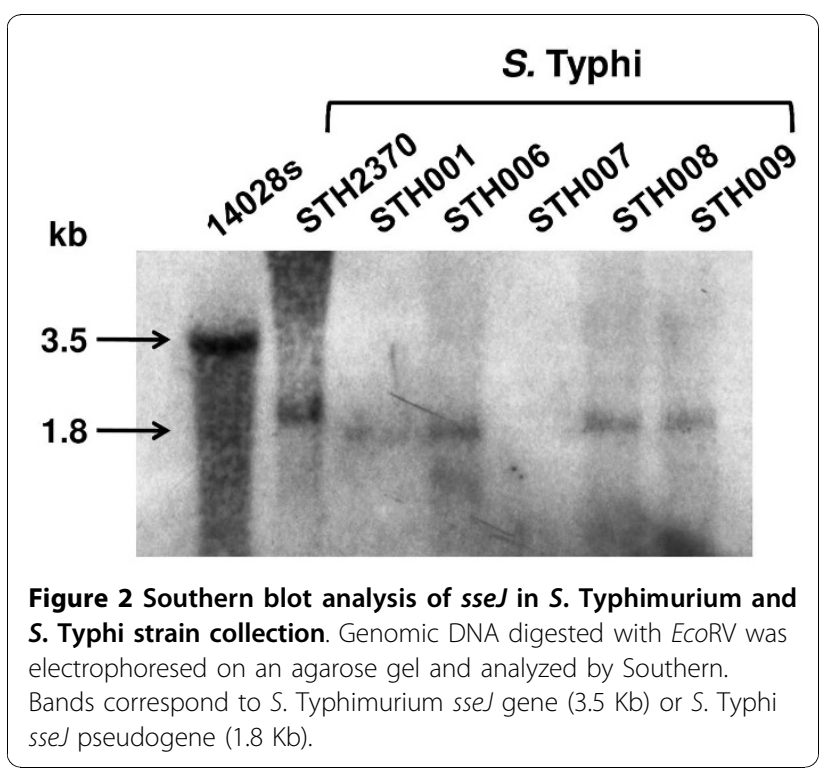

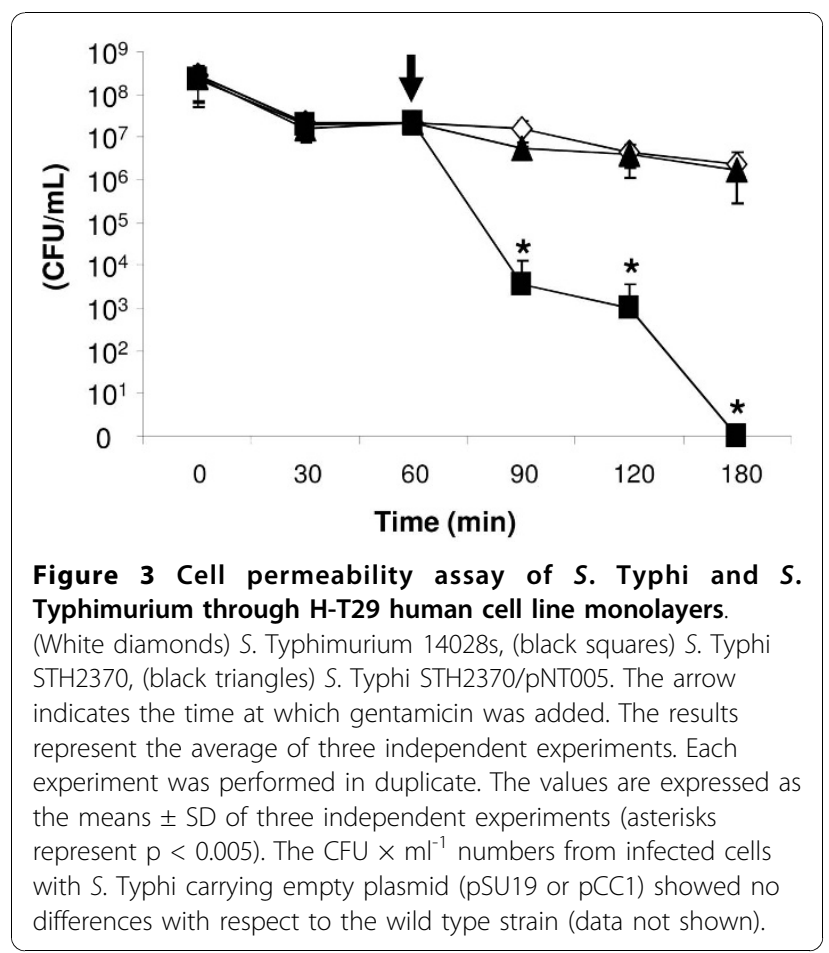

constant, marking a sharp difference with the otherwise isogenic wild type strain and highly resembling the $S$. Typhimurium phenotype (compare the white diamonds and black triangles).

In order to independently assess whether $S$. Typhi harbouring the $S$. Typhimurium sseJ gene shows a decreased disruptive effect toward cultured cell monolayers than the wild type $S$. Typhi, we measured the transepithelial electrical resistance (TER). TER is a measure of the movement of ions across the paracellular pathway. Measurement of TER across cells grown on permeable membranes can provide an indirect assessment of tight junction establishment, stability and monolayer integrity [34]. As shown in Figure 4 after $1 \mathrm{~h}$ of infection wild type $S$. Typhi efficiently disrupted the monolayer as inferred by the lower TER measured compared with the control without bacteria. However, when HT-29 cells were infected with $S$. Typhi/pNT005, TER values were similar to those obtained with $S$. Typhimurium 14028s. This result indicates that $S$. Typhi/pNT005 was less disruptive on the monolayer than $S$. Typhi wild type, supporting the result shown in Figure 3. To discard a possible gene dosage effect by the vector copy number, we infected cells with $S$. Typhi/pNT006 (complemented with a single-copy vector harbouring $s s e J_{\mathrm{STM}}$ ) and the TER obtained was similar to that of $S$. Typhi/ pNT005. This result demonstrated that the effect on cell permeability was due to the presence of sse $_{\mathrm{STM}}$ and not to an artifact produced by gene dosage. 


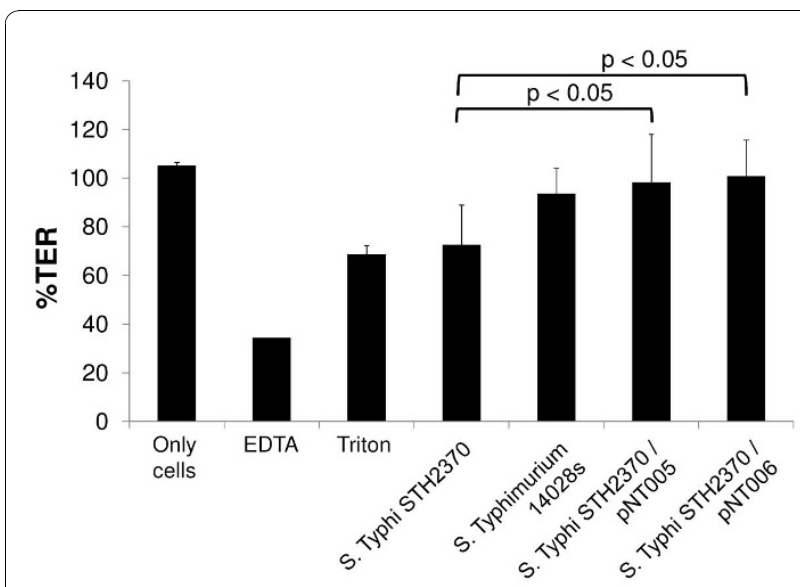

Figure 4 The presence of the sseJ gene in S. Typhi promotes the disruption of the epithelial monolayer. HT-29 cells were grown in transwells for 12-15 days. Polarised HT-29 cells were apically infected with the wild type $S$. Typhi or the respective complemented strains. TER $1 \mathrm{~h}$ post-infection reported as a percentage of the initial TER value and is expressed as the means \pm SD of three different experiments, each performed in duplicate. The percentages of TER values from cells infected with S. Typhi carrying each empty plasmid (pSU19 or pCC1) showed no differences with respect the wild type strain (data not shown).

\section{S. Typhi harbouring $s s e J_{\text {STM }}$ was less cytotoxic than wild type $S$. Typhi}

Kops et al. demonstrated that $S$. Typhi Ty2 causes rapid death of some C2BBe cells in monolayers [35]. Because cell monolayer permeability may be increased due to cell death during infection, we wanted to assess whether the presence of $\mathrm{sseJ}_{\mathrm{STM}}$ in $S$. Typhi contributes to decrease cytotoxicity, as the results of the Figure 3 and 4 strongly suggest. Cell membrane damage due to cytotoxicity leads to the release of cytoplasmic enzymes, and the measurement of lactate dehydrogenase (LDH) release is a well-accepted assay to estimate cell membrane integrity and quantify cell cytotoxicity $[36,37]$. Then, the LDH release induced by $S$. Typhimurium, $S$. Typhi, $S$. Typhi/pNT005 or $S$. Typhi/pNT006 was compared. As shown in Figure 5 we found that wild type $S$. Typhi STH2370 was the most cytotoxic strain among all bacteria tested. This result suggests that the SseJ effector protein decreased $S$. Typhi cytoxicity when bacteria interact with human cell lines, resulting in increased cell permeability.

The presence of sseJ $_{\mathrm{STM}}$ in $S$. Typhi increased bacterial intracellular retention/proliferation within HEp-2 cells It has been reported that sseJ contributes to the intracellular proliferation of $S$. Typhimurium [31,38]. Moreover, the decreased cell death produced by the presence of sse $_{\text {STM }}$ in $S$. Typhi strains (Figure 5) may lead to an increased proliferation of intracellular bacteria because

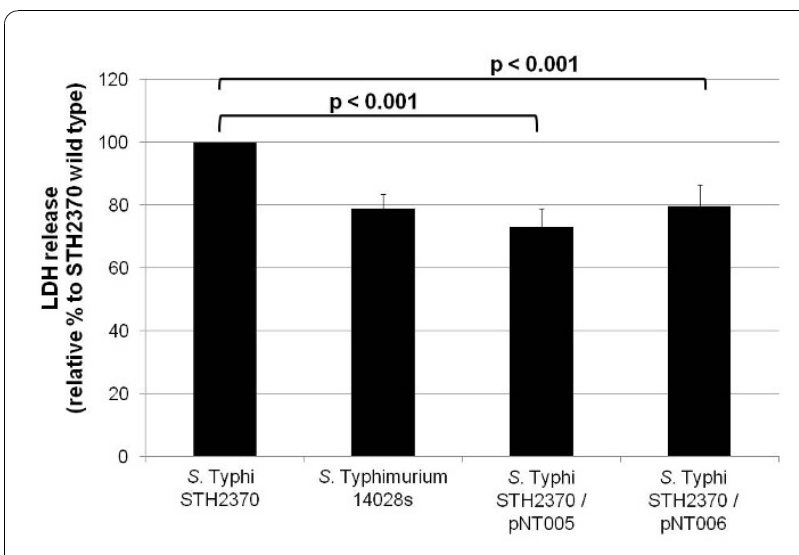

Figure 5 Analyses of cytotoxicity HT-29 infected with complemented and wild type $\mathbf{S}$. Typhi strains. HT-29 cells were grown in transwells for 12-15 days. Polarised HT-29 cells were apically infected with the $S$. Typhi wild type or the respective complemented strains. Released LDH was measured $3 \mathrm{~h}$ postinfection and reported as percentage relative to the $S$. Typhi wild type. The values correspond to the means \pm SD of three independent experiments, each performed in duplicate. The percentages of each S. Typhimurium 14028s, S. Typhi STH2370/ pNT005 and S. Typhi STH2370/pNT006, have significantly differences respect S. Typhi STH2370 wild type. LDH release from infected cells with S. Typhi carrying empty plasmid (pSU19 or pCC1) showed no differences with respect to the wild type strain (data not shown).

of a decreased cytotoxicity. A less cytotoxic pathogen should be retained inside eukaryotic cells over time, allowing an increased bacterial proliferation. If this hypothesis is correct, $S$. Typhi carrying $s s e J_{\mathrm{STM}}$ should exhibit increased CFUs in the gentamicin protection assay (see Materials and Methods). As expected, Figure 6 shows that the presence of $s s e J_{\text {STM }}$ yielded a significantly increase in the CFUs recovered from the infected cells compared to the wild type.

\section{Discussion}

In the process of adaptation to humans, genes no longer compatible with the lifestyle of $S$. Typhi within the host were selectively inactivated. These inactivated genes are called "antivirulence genes" and their loss of function results in the adaptation to a given host [39]. S. Typhi is a facultative bacterial pathogen that has accumulated a high number of pseudogenes (approximately $5 \%$ of the genome) and over $75 \%$ of them have completely lost their functions $[7,16]$. When compared with the genome of free-living organisms, facultative pathogens harbour several pseudogenes and a population structure that promotes the maintenance of the mutations. In this context, $S$. Typhi represents an intermediate step between obligate bacterial parasites and free living bacteria, exhibiting some genome erosion directed to 
inactivate and lose detrimental or non-essential functions for their environment (i.e. host) [40]. Thus, we hypothesized that the loss of some of these genes contributed to the adaptation of $S$. Typhi to the systemic infection.

Our results suggest that the loss of the fully functional SseJ protein in $S$. Typhi contributed to the adaptation to the systemic infection by increasing bacterial cytotoxicity in epithelial cells. The increased cytotoxicity presented by $S$. Typhi compared with $S$. Typhimurium is not only related to the loss of functions, as we showed here with the sseJ pseudogene; but also to the acquisition of new functions. It has been reported that $S$. Typhi presents a pathogenicity island (named SPI-18) that harbours $h l y E$. The $h l y E$ gene encodes a cytolysin that has proved to be cytotoxic toward different cell types [41-43]. SPI-18 is shared by other Salmonella enterica serovars that have been shown to cause systemic infections in humans, but is absent from $S$. Typhimurium [41]. In addition, the functional transfer of the $S$. Typhi $h l y E$ gene to $S$. Typhimurium promotes deep organ infection in mice [41]. All this evidence suggests that $S$. Typhi has been selected for an increased cytotoxicity inside its host in order to perform a successful systemic infection. Thus, an increased cytotoxicity toward the epithelial barrier may guarantee the development of a deeper infection and a decreased retention inside epithelial cells at the bacterial entry point.

On the other hand, the presence of the sse $_{S T M}$ gene in $S$. Typhi significantly enhances the retention time within epithelial cells and/or the intracellular proliferation as we showed in Figure 6 in agreement with previous reports that indicate that SseJ enzymatic activity

contributes to intracellular replication in host tissues $[31,38]$. Accordingly, it is possible that the sseJ loss of function was selected in $S$. Typhi in order to promote a decreased retention/proliferation of bacteria inside the eukaryotic cells. It is known that the intracellular proliferation is essential for the virulence of $S$. Typhimurium [44]. Nevertheless, recent studies revealed that the magnitude of the $\mathrm{CD}^{+} \mathrm{T}$ cell response correlates directly to the intracellular proliferation in Salmonella enterica, showing that a reduced intracellular proliferation limits antigen presentation and development of a rapid $\mathrm{CD} 8^{+}$ $\mathrm{T}$ cell response, indicating that reduced intracellular proliferation of virulent pathogens may be an important mechanism of immune evasion. [45]. Accordingly, Salmonella presents several responses directed to downregulate the intracellular proliferation, reinforcing the concept that a state of low proliferation within the host cell is strategy to enhance virulence in a determined niche [46]. Actually, it has been shown that Salmonella

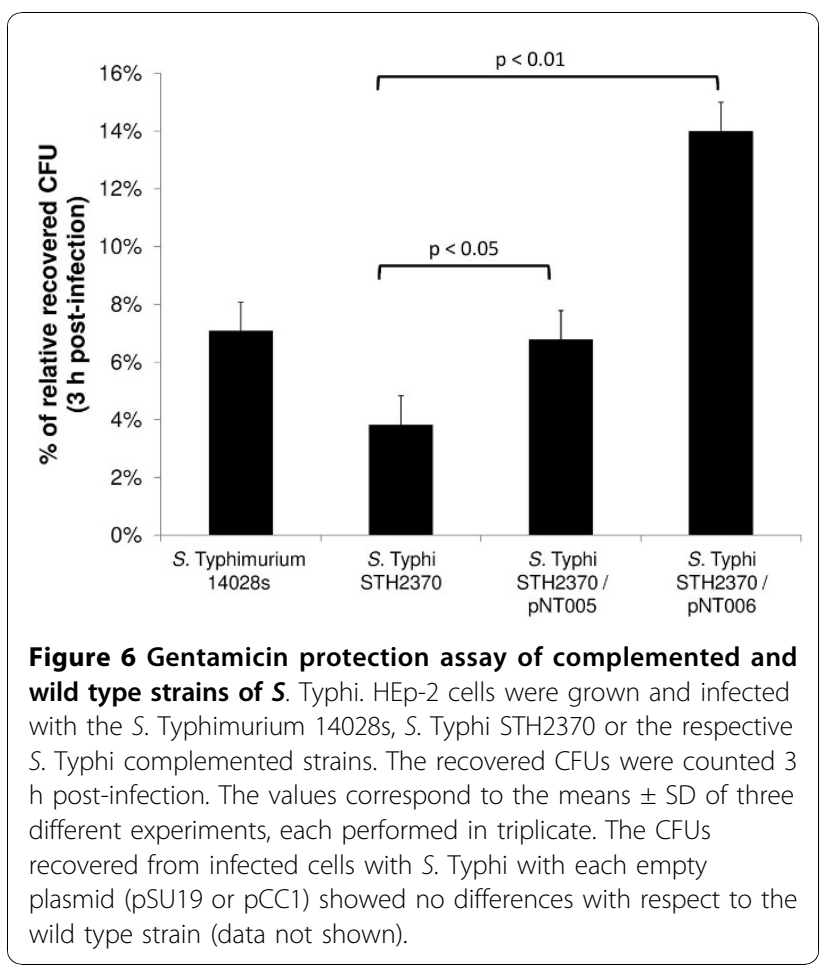

expands its population in the liver by increasing the number of infection foci rather than undergoing massive intracellular growth in individual host cells, where the bacterial spreading from the initial infection foci to nearby cells may be facilitated by inducing cytotoxic effects in the infected cells $[47,48]$.

How sse $_{S T M}$ reduces the cytotoxicity in $S$. Typhi is not clear. It is known that the lipid imbalance associated to the presence of lipid alcohols, fatty acid and sterols is related to cytotoxicity and apoptosis $[49,50]$. Any process that limits the accumulation of these species is likely to be cytoprotective [50]. One such process involves the presence of different acyltransferase gene families that generate neutral lipids or steryl esters from these lipid alcohols [50]. SseJ, that presents glycerophospholipid: cholesterol acyltransferase (GCAT) activity in eukaryotic cells [51], might plausibly contribute to the reduction of the lipid-associated cytoxicity. The precise mechanisms underlying this process is unknown, but one possibility is that the presence of $s s e J_{S T M}$ in $S$. Typhi is affecting the lipid remodelling in the infected cells, in turn reducing the cytotoxicity.

All our results together suggest that the loss of the sseJ gene in $S$. Typhi contributed to the adaptation to the systemic infection by increasing the bacterialinduced cytotoxicity and by decreasing the retention/ proliferation inside the epithelial cells. 


\section{Conclusions}

Based on our results we conclude that the mutation that inactivate the sseJ gene in $S$. Typhi resulted in evident changes in the behaviour of bacteria in contact with eukaryotic cells, plausibly contributing to the $S$. Typhi adaptation to the systemic infection in humans.

\section{Methods}

Bacterial strains, media and growth conditions

The $S$. Typhi and $S$. Typhimurium strains used in this study are described in Table 2 . Strains were routinely grown in Luria-Bertani (LB) medium (Bacto Tryptone $10 \mathrm{~g}^{-1}$; Bacto Yeast Extract $5 \mathrm{~g} \times \mathrm{l}^{-1}, \mathrm{NaCl} 5 \mathrm{~g} \times \mathrm{l}^{-1}$ ) at $37^{\circ} \mathrm{C}$, with vigorous shaking, or anaerobically by adding an overlay of $500 \mu \mathrm{l}$ of sterile mineral oil as a barrier to oxygen prior to invasion assays with cultured human cells. When required, the medium was supplemented with antibiotics at the following concentrations: chloramphenicol $20 \mu \mathrm{g} \times \mathrm{ml}^{-1}$, ampicillin $100 \mu \mathrm{g} \times \mathrm{ml}^{-1}$ and kanamycin $50 \mu \mathrm{g} \times \mathrm{ml}^{-1}$. Media were solidified by the addition of agar (15 $\mathrm{g} \times \mathrm{l}^{-1}$ Bacto agar).

\section{Construction of plasmids}

The sseJ PCR product was initially cloned into pGEM-T Easy (Promega) to yield plasmid pNT002, and the presence of the gene was confirmed by PCR amplification and restriction endonuclease assays. The DNA fragment containing the sseJ gene was obtained from pNT002 and cloned into the EcoRI site of the medium-copy number vector pSU19 [52] to yield the plasmid pNT005. The presence of the gene and its promoter region was confirmed in all plasmids by PCR amplification and restriction endonuclease analyses. The PCR product was directly cloned in the $\mathrm{pCC} 1$ vector according to manufacturer's instructions (CopyControl ${ }^{\text {six }}$ PCR Cloning Kit, Stratagene) to yield the plasmid pNT006. The expression of sseJ gene from each plasmid was confirmed by Western blotting (data not shown).

\section{Bioinformatic analyses}

Comparative sequence analyses were made with the complete genome sequences of $S$. enterica serovar Typhi strains CT18 (GenBank: AL627270.1) and Ty2 (GenBank: AL513382), serovar Typhimurium LT2 (GenBank: AE006468.1). The sequences were analyzed using the BLAST, alignment, and phylogeny tools available at http://www.ncbi.nlm.nih.gov/ and by visual inspection to improve alignments.

\section{PCR amplification}

PCR amplifications were performed using an Eppendorf thermal cycler and Taq DNA polymerase (Invitrogen Cat. $\mathrm{N}^{\circ}$ 11615-010). Reaction mixtures contained $1 \times$ PCR buffer, $1.5 \mathrm{mM} \mathrm{MgCl}_{2}$, each dNTP $(200 \mathrm{mM})$, primers $(1 \mathrm{mM}), 100 \mathrm{ng}$ of template DNA, and $2 \mathrm{U}$ polymerase. Standard conditions for amplification were 30 cycles at $94^{\circ} \mathrm{C}$ for 30 seconds, $62^{\circ} \mathrm{C}$ for $1 \mathrm{~min}$ and $72^{\circ} \mathrm{C}$ for 2 min 30 seconds, followed by a final extension step

Table 2 Bacteria strains and plasmids used in this study

\begin{tabular}{|c|c|c|}
\hline Strain or plasmid & Relevant characteristic & Reference or Source \\
\hline \multicolumn{3}{|l|}{ Strains } \\
\hline \multicolumn{3}{|c|}{ Serovar Typhimurium } \\
\hline ATCC14028s & Wild-type strain, virulent & ATCC \\
\hline $\mathrm{LT} 2$ & Wild-type strain & S. Maloy \\
\hline \multicolumn{3}{|l|}{ Serovar Typhi } \\
\hline STH2370 & Clinical strain, virulent & Hospital Dr Lucio Córdova \\
\hline STH001 & Clinical strain, virulent & Hospital Dr Lucio Córdova \\
\hline STH004 & Clinical strain, virulent & Hospital Dr Lucio Córdova \\
\hline STH005 & Clinical strain, virulent & Hospital Dr Lucio Córdova \\
\hline STH006 & Clinical strain, virulent & Hospital Dr Lucio Córdova \\
\hline STH007 & Clinical strain, virulent & Hospital Dr Lucio Córdova \\
\hline STH008 & Clinical strain, virulent & Hospital Dr Lucio Córdova \\
\hline STH009 & Clinical strain, virulent & Hospital Dr Lucio Córdova \\
\hline Ty2 & Wild-type strain & Instituto de Salud Pública \\
\hline \multicolumn{3}{|l|}{ Plasmids } \\
\hline pGEM-Teasy & High-copy-number cloning vector & Promega \\
\hline $\mathrm{pCC} 1$ & Single-copy vector, F plasmid derived & Stratagene \\
\hline pNT002 & pGEM-Teasy carrying the S. Typhimurium sseJ gene & This work \\
\hline pSU19 & Medium-copy-number cloning vector & {$[52]$} \\
\hline pNT005 & pSU19 carrying the S. Typhimurium sseJ gene & This work \\
\hline pNT006 & pCC1 carrying the S. Typhimurium sseJ gene & This work \\
\hline
\end{tabular}


at $72^{\circ} \mathrm{C}$ for $10 \mathrm{~min}$. Template $S$. Typhi chromosomal DNA was prepared as described [53]. Primers SseJ1Tym (CATTGTATGTATTTTATTGGCGACG) and SseJ2Tym (AATCGGCAGCAAAGATAGCA) were used to amplify $1460 \mathrm{bp}$, and were designed from the $S$. Typhimurium LT2 sseJ reported sequence. The conditions for amplification of $127 \mathrm{bp}$ were 30 cycles at $94^{\circ} \mathrm{C}$ for 30 seconds, $53^{\circ} \mathrm{C}$ for 30 seconds and $72^{\circ} \mathrm{C}$ for $1 \mathrm{~min}$, followed by a final extension step at $72^{\circ} \mathrm{C}$ for $10 \mathrm{~min}$. Primers SseJRT1 (GCTAAAGACCCTCAGCTAGA) and SseJRT2 (CAGTGGAATAATGATGAGCT) were designed from the $S$. Typhimurium LT2 sseJ reported sequence.

\section{Southern hybridisations}

Hybridisation probes for $s s e J$ were generated by PCR amplification and were purified and labelled using the Detector $^{\text {tix }}$ Random Primer DNA Biotinylation Kit (KPL). Genomic DNA from Salmonella serovars was prepared as described by Maloy [54], cleaved with EcoRV (Invitrogen) and the fragments were resolved on a $0.8 \%$ agarose gel. The DNA was then transferred to a nylon membrane and cross-linked by UV irradiation. Hybridisation was performed according to the protocol described in the chemiluminescent system, using a DNA Detector ${ }^{\mathrm{mm}}$ HRP Southern Blotting Kit (KPL) and Kodak XAR-5 film.

\section{Cell permeability assay}

We used an in vitro assay modified from the method described by McCormick [55]. Briefly, the colon carcinoma HT-29 cell line was grown to confluence (18-21 days) on $3.0 \mu \mathrm{m}$ pore-size filters ("transwells", Millicell", Millipore) with glucose-free RPMI (Gibco). Each transwell was inoculated individually to the apical surface with $400 \mu \mathrm{l}$ of approximately $1 \times 10^{7} \mathrm{CFU} \mathrm{m}^{-1}$ of bacterial cultures and immediately incubated for $60 \mathrm{~min}$ at $37^{\circ} \mathrm{C}$. After extensive washing with sterile PBS $(\mathrm{NaCl}$ $0.8 \% \mathrm{w} / \mathrm{v} ; \mathrm{KCl} 0.02 \% \mathrm{w} / \mathrm{v} ; \mathrm{Na}_{2} \mathrm{HPO}_{4} 2 \mathrm{H}_{2} \mathrm{O} 0.13 \% \mathrm{w} / \mathrm{v}$; $\mathrm{KH}_{2} \mathrm{PO}_{4} 0.02 \% \mathrm{w} / \mathrm{v}$ ), the extracellular bacteria were killed by treatment of monolayers with gentamicin (50 $\left.\mu \mathrm{g} \times \mathrm{ml}^{-1}\right)$. Immediately after gentamicin treatment, the medium from basal compartment of the epithelial cell monolayer was collected and plated for colony forming units (CFU) to assess the number of bacteria that passed through the cell monolayer. The polarisation of cells was confirmed by transepithelial electrical resistance (TER) and transmission electron microscopy (data not shown).

\section{Transepithelial electrical resistance}

TER was used to monitor changes in epithelial cell culture integrity. TER in HT-29 enterocytes was studied using an EVOM electrode (World Precision Instru- ments). The enterocytes were grown to confluence (1821 days) on $3.0 \mu \mathrm{m}$ pore-size filters ("transwells", Millicell $^{\circ}$, Millipore). The electrical resistance readings were recorded after subtracting the average resistance of two membranes in the absence of enterocytes at the beginning of the assay $\left(t_{0}\right)$ and $1 \mathrm{~h}$ post-infection $\left(t_{1}\right)$. Controls included the incubation of the cells with EDTA and Triton X-100 (1\% PBS). The reading was expressed as percentages and calculated as follows:

$$
\% \operatorname{TER}(1 \mathrm{~h})=100 \times\left(\text { TER }_{0} \times \text { TER }_{1}{ }^{-1}\right)
$$

We verified the HT-29 polarisation by TER and transmission electron microscopy.

\section{LDH Cytotoxicity Assay}

Cytotoxicity of infected HT-29 cells was assayed using a lactate dehydrogenase (LDH) Kit (Valtek), which measures the extracellular release of LDH into the media by dead cells, according to the manufacturer's instructions. The absorbance values of treated cells were expressed as a percentage relative to the wild type $S$. Typhi after correcting for background from media without cells at $340 \mathrm{~nm}$.

\section{Gentamicin protection Assay}

To measure bacterial invasion, the method described by Lissner [56] and modified by Contreras [57] was used. Briefly, HEp- 2 monolayers $\left(5 \times 10^{5}\right.$ cells/well $)$ were grown at $37^{\circ} \mathrm{C}$ in a $5 \% \mathrm{CO}_{2} / 95 \%$ air mixture in RPMIFS (RPMI medium supplemented with $10 \%$ fetal bovine serum pre-treated for $30 \mathrm{~min}$ at $60^{\circ} \mathrm{C}$ ). The tested bacterial strains were grown anaerobically to mid-exponential phase and then harvested by centrifugation prior to infect the monolayers in 96-well microtiter plates at a multiplicity of infection of 100:1. After incubation of $1 \mathrm{~h}$ to allow bacterial entry into the cells, monolayers were washed twice with phosphate-buffered saline (PBS), and $100 \mu \mathrm{L}$ of RPMI containing gentamicin $\left(200 \mu \mathrm{g} \times \mathrm{ml}^{-1}\right)$ was added to each well. The plates were then incubated for $2 \mathrm{~h}$ to kill any remaining extracellular bacteria. In the case of the strains carrying vectors, the medium was supplemented additionally with chloramphenicol during the entire assay. The medium was removed and cells were washed twice with PBS. Then, the cells were lysed with sodium deoxycholate $(0.5 \% \mathrm{w} / \mathrm{v}$, in PBS). The number of intracellular bacteria (CFU at $t_{3}$ ) was determined plating onto LB agar plates with chloramphenicol (the strains carrying plasmid) or without antibiotic (the wild type strains). Quantitative invasion assay values were calculated as follows:

$3 \mathrm{~h}$ post infection index $=100 \times\left(\right.$ intracellular $\mathrm{CFU} \mathrm{mL} \mathrm{m}^{-1}$ at $\mathrm{t}_{3} \times \mathrm{CFU} \mathrm{mL} \mathrm{L}^{-1}$ added $)$ 


\section{Statistics}

All results are expressed as means $\pm \mathrm{SD}$ of an individual experiment performed in triplicate. $P$ values were calculated according to Student's $t$-test, and values $\mathrm{p}<0.05$ or $\mathrm{p}<0.01$ were considered statistically significant.

\section{Acknowledgements}

UNAB Grant DI-05/I (A.T) and FONDECYT Grant 1060999 (G.M).

\section{Authors' contributions}

AT: designed the studies, performed the experiments and wrote the manuscript; LB: performed the transepithelial electrical resistance experiment, contributing significantly in the development of the other experiments and in the preparation of manuscript; JAF: participated in writing the paper; GCM: designed the studies and participated in the revision of the manuscript. All authors read and approved the final manuscript.

Received: 22 September 2010 Accepted: 7 December 2010 Published: 7 December 2010

\section{References}

1. Parry CM, Hien TT, Dougan G, White NJ, Farrar JJ: Typhoid fever. N Engl J Med 2002, 347(22):1770-1782

2. Tsolis RM, Kingsley RA, Townsend SM, Ficht TA, Adams LG, Baumler AJ: Of mice, calves, and men. Comparison of the mouse typhoid model with other Salmonella infections. Adv Exp Med Biol 1999, 473:261-274.

3. Zhang S, Kingsley RA, Santos RL, Andrews-Polymenis H, Raffatellu M, Figueiredo J, Nunes J, Tsolis RM, Adams LG, Baumler AJ: Molecular pathogenesis of Salmonella enterica serotype typhimurium-induced diarrhea. Infect Immun 2003, 71(1):1-12.

4. Andersson JO, Andersson SG: Insights into the evolutionary process of genome degradation. Curr Opin Genet Dev 1999, 9(6):664-671.

5. Moran NA, Plague GR: Genomic changes following host restriction in bacteria. Curr Opin Genet Dev 2004, 14(6):627-633.

6. Mathee K, Narasimhan G, Valdes C, Qiu X, Matewish JM, Koehrsen M, Rokas A, Yandava CN, Engels R, Zeng E, et al: Dynamics of Pseudomonas aeruginosa genome evolution. Proc Natl Acad Sci USA 2008, 105(8):3100-3105.

7. Dagan T, Blekhman R, Graur D: The "domino theory" of gene death: gradual and mass gene extinction events in three lineages of obligate symbiotic bacterial pathogens. Mol Biol Evol 2006, 23(2):310-316.

8. Arber W: Genetic variation: molecular mechanisms and impact on microbial evolution. FEMS Microbiol Rev 2000, 24(1):1-7.

9. Ochman $\mathrm{H}$, Moran NA: Genes lost and genes found: evolution of bacterial pathogenesis and symbiosis. Science 2001, 292(5519):1096-1099.

10. Nakata N, Tobe T, Fukuda I, Suzuki T, Komatsu K, Yoshikawa M, Sasakawa C: The absence of a surface protease, OmpT, determines the intercellular spreading ability of Shigella: the relationship between the ompT and kcpA loci. Mol Microbiol 1993, 9(3):459-468.

11. Chart H, Conway D, Rowe B: Outer membrane characteristics of Salmonella enteritidis phage type 4 growing in chickens. Epidemiol Infect 1993, 111(3):449-454

12. Duguid JP, Anderson ES, Alfredsson GA, Barker R, Old DC: A new biotyping scheme for Salmonella typhimurium and its phylogenetic significance. $J$ Med Microbiol 1975, 8(1):149-166.

13. Li J, Smith NH, Nelson K, Crichton PB, Old DC, Whittam TS, Selander RK: Evolutionary origin and radiation of the avian-adapted non-motile salmonellae. J Med Microbiol 1993, 38(2):129-139.

14. Baumler AJ, Tsolis RM, Ficht TA, Adams LG: Evolution of host adaptation in Salmonella enterica. Infect Immun 1998, 66(10):4579-4587.

15. Deng W, Liou SR, Plunkett G, Mayhew GF, Rose DJ, Burland V, Kodoyianni V, Schwartz DC, Blattner FR: Comparative genomics of Salmonella enterica serovar Typhi strains Ty2 and CT18. J Bacteriol 2003, 185(7):2330-2337.

16. McClelland M, Sanderson KE, Clifton SW, Latreille P, Porwollik S, Sabo A, Meyer R, Bieri T, Ozersky P, McLellan M, et al: Comparison of genome degradation in Paratyphi $A$ and Typhi, human-restricted serovars of Salmonella enterica that cause typhoid. Nat Genet 2004, 36(12):1268-1274.
17. Lee AK, Detweiler CS, Falkow S: OmpR regulates the two-component system SsrA-ssrB in Salmonella pathogenicity island 2. J Bacteriol 2000, 182(3):771-781.

18. $\mathrm{Xu} X$, Hensel M: Systematic analysis of the SsrAB virulon of Salmonella enterica. Infect Immun 2010, 78(1):49-58.

19. Hensel M, Shea JE, Waterman SR, Mundy R, Nikolaus T, Banks G, VazquezTorres A, Gleeson C, Fang FC, Holden DW: Genes encoding putative effector proteins of the type III secretion system of Salmonella pathogenicity island 2 are required for bacterial virulence and proliferation in macrophages. Mol Microbiol 1998, 30(1):163-174.

20. Hensel M: Salmonella pathogenicity island 2. Mol Microbiol 2000, 36(5):1015-1023

21. Ochman H, Soncini FC, Solomon F, Groisman EA: Identification of a pathogenicity island required for Salmonella survival in host cells. Proc Natl Acad Sci USA 1996, 93(15):7800-7804.

22. Steele-Mortimer O: The Salmonella-containing vacuole: moving with the times. Curr Opin Microbiol 2008, 11(1):38-45.

23. Brumell JH, Tang P, Mills SD, Finlay BB: Characterization of Salmonellainduced filaments (Sifs) reveals a delayed interaction between Salmonella-containing vacuoles and late endocytic compartments. Traffic 2001, 2(9):643-653.

24. Kuhle V, Hensel M: SseF and SseG are translocated effectors of the type III secretion system of Salmonella pathogenicity island 2 that modulate aggregation of endosomal compartments. Cell Microbiol 2002, 4(12):813-824.

25. Ruiz-Albert J, Yu XJ, Beuzon CR, Blakey AN, Galyov EE, Holden DW: Complementary activities of SseJ and SifA regulate dynamics of the Salmonella typhimurium vacuolar membrane. Mol Microbiol 2002, 44(3):645-661.

26. Jiang X, Rossanese OW, Brown NF, Kujat-Choy S, Galan JE, Finlay BB, Brumell JH: The related effector proteins SopD and SopD2 from Salmonella enterica serovar Typhimurium contribute to virulence during systemic infection of mice. Mol Microbiol 2004, 54(5):1186-1198.

27. Beuzon CR, Meresse S, Unsworth KE, Ruiz-Albert J, Garvis S, Waterman SR, Ryder TA, Boucrot E, Holden DW: Salmonella maintains the integrity of its intracellular vacuole through the action of SifA. EMBO J 2000 19(13):3235-3249.

28. Freeman JA, OhI ME, Miller SI: The Salmonella enterica serovar typhimurium translocated effectors SseJ and SifB are targeted to the Salmonella-containing vacuole. Infect Immun 2003, 71(1):418-427.

29. Raffatellu M, Wilson RP, Chessa D, Andrews-Polymenis $H$, Tran QT, Lawhon S, Khare S, Adams LG, Baumler AJ: SipA, SopA, SopB, SopD, and SopE2 contribute to Salmonella enterica serotype typhimurium invasion of epithelial cells. Infect Immun 2005, 73(1):146-154.

30. García-del Portillo F: Interaction of Salmonella with lysosomes of eukaryotic cells. Microbiologia 1996, 12(2):259-266.

31. Ohlson MB, Fluhr K, Birmingham CL, Brumell JH, Miller SI: SseJ deacylase activity by Salmonella enterica serovar Typhimurium promotes virulence in mice. Infect Immun 2005, 73(10):6249-6259.

32. Parkhill J, Dougan G, James KD, Thomson NR, Pickard D, Wain J, Churcher C, Mungall KL, Bentley SD, Holden MT, et al: Complete genome sequence of a multiple drug resistant Salmonella enterica serovar Typhi CT18. Nature 2001, 413(6858):848-852.

33. McClelland M, Sanderson KE, Spieth J, Clifton SW, Latreille P, Courtney L, Porwollik S, Ali J, Dante M, Du F, et al: Complete genome sequence of Salmonella enterica serovar Typhimurium LT2. Nature 2001, 413(6858):852-856

34. Pedemonte $\mathrm{CH}$ : Inhibition of $\mathrm{Na}(+)$-pump expression by impairment of protein glycosylation is independent of the reduced sodium entry into the cell. J Membr Biol 1995, 147(3):223-231.

35. Kops SK, Lowe DK, Bement WM, West AB: Migration of Salmonella typhi through intestinal epithelial monolayers: an in vitro study. Microbiol Immunol 1996, 40(11):799-811.

36. Mosmann T: Rapid colorimetric assay for cellular growth and survival: application to proliferation and cytotoxicity assays. $J$ Immunol Methods 1983, 65(1-2):55-63.

37. Arechabala B, Coiffard C, Rivalland P, Coiffard $L$, de Roeck-Holtzhauer Y: Comparison of cytotoxicity of various surfactants tested on normal human fibroblast cultures using the neutral red test, MTT assay and LDH release. J Appl Toxicol 1999, 19(3):163-165. 
38. Nawabi P, Catron DM, Haldar K: Esterification of cholesterol by a type III secretion effector during intracellular Salmonella infection. Mol Microbiol 2008, 68(1):173-185.

39. Maurelli AT: Black holes, antivirulence genes, and gene inactivation in the evolution of bacterial pathogens. FEMS Microbiol Lett 2007, 267(1):1-8.

40. Ochman H, Davalos LM: The nature and dynamics of bacterial genomes. Science 2006, 311(5768):1730-1733.

41. Fuentes JA, Villagra N, Castillo-Ruiz M, Mora GC: The Salmonella Typhi hlyE gene plays a role in invasion of cultured epithelial cells and its functional transfer to $S$. Typhimurium promotes deep organ infection in mice. Res Microbiol 2008, 159(4):279-287.

42. Oscarsson J, Westermark M, Lofdahl S, Olsen B, Palmgren $\mathrm{H}$, Mizunoe $\mathrm{Y}$, Wai SN, Uhlin BE: Characterization of a pore-forming cytotoxin expressed by Salmonella enterica serovars typhi and paratyphi A. Infect Immun 2002, 70(10):5759-5769.

43. Faucher SP, Forest C, Beland M, Daigle F: A novel PhoP-regulated locus encoding the cytolysin ClyA and the secreted invasin TaiA of Salmonella enterica serovar Typhi is involved in virulence. Microbiology 2009, 155(Pt 2):477-488

44. Leung KY, Finlay BB: Intracellular replication is essential for the virulence of Salmonella typhimurium. Proc Natl Acad Sci USA 1991 88(24):11470-11474.

45. Albaghdadi H, Robinson N, Finlay B, Krishnan L, Sad S: Selectively reduced intracellular proliferation of Salmonella enterica serovar typhimurium within APCs limits antigen presentation and development of a rapid CD8 T cell response. J Immunol 2009, 183(6):3778-3787.

46. Tiérrez A, García-del Portillo F: New concepts in Salmonella virulence: the importance of reducing the intracellular growth rate in the host. Cell Microbiol 2005, 7(7):901-909.

47. Monack DM, Hersh D, Ghori N, Bouley D, Zychlinsky A, Falkow S: Salmonella exploits caspase-1 to colonize Peyer's patches in a murine typhoid model. J Exp Med 2000, 192(2):249-258.

48. Sheppard M, Webb C, Heath F, Mallows V, Emilianus R, Maskell D, Mastroeni P: Dynamics of bacterial growth and distribution within the liver during Salmonella infection. Cell Microbiol 2003, 5(9):593-600.

49. Kellner-Weibel G, Luke SJ, Rothblat GH: Cytotoxic cellular cholesterol is selectively removed by apoA-I via ABCA1. Atherosclerosis 2003, 171(2):235-243.

50. Garbarino J, Padamsee M, Wilcox L, Oelkers PM, D'Ambrosio D, Ruggles KV, Ramsey N, Jabado O, Turkish A, Sturley SL: Sterol and diacylglycerol acyltransferase deficiency triggers fatty acid-mediated cell death. J Biol Chem 2009, 284(45):30994-31005.

51. Lossi NS, Rolhion N, Magee Al, Boyle C, Holden DW: The Salmonella SPI-2 effector SseJ exhibits eukaryotic activator-dependent phospholipase A and glycerophospholipid: cholesterol acyltransferase activity. Microbiology 2008, 154(Pt 9):2680-2688.

52. Martínez E, Bartolomé B, de la Cruz F: pACYC184-derived cloning vectors containing the multiple cloning site and lac $Z$ alpha reporter gene of pUC8/9 and pUC18/19 plasmids. Gene 1988, 68(1):159-162.

53. Santiviago CA, Toro CS, Bucarey SA, Mora GC: A chromosomal region surrounding the $o m p D$ porin gene marks a genetic difference between Salmonella typhi and the majority of Salmonella serovars. Microbiology 2001, 147(Pt 7):1897-1907.

54. Maloy SR: From Southern DNA hybridization to map TnphoA insertions. In Genetic analysis of pathogenic bacteria: A laboratory manual. Edited by: Maloy SR, Stewart VJ, Taylor RK. New York: Cold Spring Harbor Laboratory Press edn; 1996:408.

55. McCormick BA, Colgan SP, Delp-Archer C, Miller SI, Madara JL: Salmonella typhimurium attachment to human intestinal epithelial monolayers: transcellular signalling to subepithelial neutrophils. J Cell Biol 1993, 123(4):895-907.

56. Lissner CR, Swanson RN, O'Brien AD: Genetic control of the innate resistance of mice to Salmonella typhimurium: expression of the Ity gene in peritoneal and splenic macrophages isolated in vitro. J Immunol 1983, 131(6):3006-3013.
57. Contreras I, Toro CS, Troncoso G, Mora GC: Salmonella typhi mutants defective in anaerobic respiration are impaired in their ability to replicate within epithelial cells. Microbiology 1997, 143(Pt 8):2665-2672.

doi:10.1186/1471-2180-10-312

Cite this article as: Trombert et al:: S. Typhimurium sseJ gene decreases the S. Typhi cytotoxicity toward cultured epithelial cells. BMC

Microbiology 2010 10:312.

\section{Submit your next manuscript to BioMed Central and take full advantage of:}

- Convenient online submission

- Thorough peer review

- No space constraints or color figure charges

- Immediate publication on acceptance

- Inclusion in PubMed, CAS, Scopus and Google Scholar

- Research which is freely available for redistribution

Submit your manuscript at www.biomedcentral.com/submit
C Biomed Central 